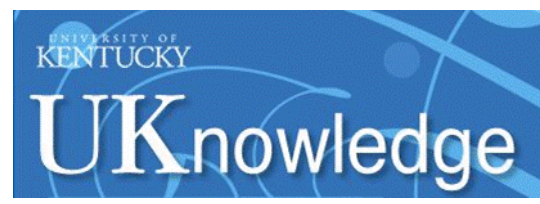

University of Kentucky

UKnowledge

Internal Medicine Faculty Publications

Internal Medicine

2-20-2014

\title{
Fundamentals of Lung Auscultation
}

Abraham Bohadana

Shaare Zedek Medical Center, Israel

Gabriel Izbicki

Shaare Zedek Medical Center, Israel

Steve S. Kraman

University of Kentucky, sskram01@email.uky.edu

Follow this and additional works at: https://uknowledge.uky.edu/internalmedicine_facpub

Part of the Medicine and Health Sciences Commons

Right click to open a feedback form in a new tab to let us know how this document benefits you.

\section{Repository Citation}

Bohadana, Abraham; Izbicki, Gabriel; and Kraman, Steve S., "Fundamentals of Lung Auscultation" (2014). Internal Medicine Faculty Publications. 61.

https://uknowledge.uky.edu/internalmedicine_facpub/61

This Article is brought to you for free and open access by the Internal Medicine at UKnowledge. It has been accepted for inclusion in Internal Medicine Faculty Publications by an authorized administrator of UKnowledge. For more information, please contact UKnowledge@lsv.uky.edu. 


\section{Fundamentals of Lung Auscultation}

Digital Object Identifier (DOI)

http://dx.doi.org/10.1056/NEJMra1302901

\section{Notes/Citation Information}

Published in The New England Journal of Medicine, v. 370, no. 8, p. 744-751.

From The New England Journal of Medicine, Abraham Bohadana, Gabriel Izbicki, and Steve S. Kraman, Fundamentals of Lung Auscultation, 370, 744-751. Copyright @ 2014 Massachusetts Medical Society. Reprinted with permission. 


\title{
Fundamentals of Lung Auscultation
}

\author{
Abraham Bohadana, M.D., Gabriel Izbicki, M.D., and Steve S. Kraman, M.D.
}

From the Pulmonary Institute, Shaare Zedek Medical Center, and the Hebrew University Hadassah Medical School, Jerusalem (A.B., G.I.); and the University of Kentucky School of Medicine, Lexington (S.S.K.). Address reprint requests to Dr. Bohadana at the Pulmonary Institute, Shaare Zedek Medical Center, 12 Baiyt St., 91031 Jerusalem, Israel, or at abraham.bohadana@gmail.com.

N EnglJ Med 2014;370:744-51. DOI: 10.1056/NEJMra1302901

Copyright ( 2014 Massachusetts Medical Society.
An interactive graphic is available at NEJM.org

\section{NOMENCLATURE}

The traditional nomenclature for lung sounds suffers from imprecision. Therefore, in this article, we have adopted the terminology proposed by the ad hoc committee of the International Lung Sounds Association. ${ }^{2}$ In this classification of lung sounds, the term "rale" is replaced by "crackle," since the adjectives often used to qualify rales (e.g., "moist" or "dry") can be misleading with regard to the means by which rales (or crackles) are produced. "Crackle" can be defined acoustically and does not suggest any means or site of generation. The clinical characteristics of normal and adventitious sounds are summarized in Table 1, and the lung sounds can be heard in an interactive graphic, available with the full text of this article at NEJM.org.

NORMAL RESPIRATORY SOUNDS

\section{TRACHEAL SOUNDS}

Tracheal auscultation is not frequently performed, but in certain situations it can convey important clinical information. When heard at the suprasternal notch or the lateral neck, normal tracheal sounds characteristically contain a large amount of sound energy and are easily heard during the two phases of the respiratory cycle (Fig. 1A). The frequencies of these sounds range from $100 \mathrm{~Hz}$ to almost $5000 \mathrm{~Hz}$, with a sharp drop in power at a frequency of approximately $800 \mathrm{~Hz}$ and little energy beyond $1500 \mathrm{~Hz} .{ }^{4}$ They are produced by turbulent airflow in the pharynx, glottis, and subglottic region.

Listening to tracheal sounds can be useful in a variety of circumstances. First, the trachea carries sound from within the lungs, allowing auscultation of other sounds without filtering from the chest cage. Second, the characteristics of tracheal sounds are similar in quality to the abnormal bronchial breathing heard 
in patients with lung consolidation. Third, in tense wheeze. Recognizing this "tracheal wheeze" patients with upper-airway obstruction, tracheal is clinically important because when ausculsounds can become frankly musical, character- tated over the lung, it is often mistakenly taken ized as either a typical stridor or a localized, in- for the wheeze of asthma (as discussed in more

\begin{tabular}{|c|c|c|}
\hline Respiratory Sound & Clinical Characteristics & Clinical Correlation \\
\hline Normal tracheal sound & $\begin{array}{l}\text { Hollow and nonmusical, clearly heard in both phases } \\
\text { of respiratory cycle }\end{array}$ & $\begin{array}{l}\text { Transports intrapulmonary sounds, indicating upper- } \\
\text { airway patency; can be disturbed (e.g., become } \\
\text { more noisy or even musical) if upper-airway } \\
\text { patency is altered; used to monitor sleep apnea; } \\
\text { serves as a good model of bronchial breathing }\end{array}$ \\
\hline Normal lung sound & $\begin{array}{l}\text { Soft, nonmusical, heard only on inspiration and on } \\
\text { early expiration }\end{array}$ & $\begin{array}{l}\text { Is diminished by factors affecting sound generation } \\
\text { (e.g., hypoventilation, airway narrowing) or sound } \\
\text { transmission (e.g., lung destruction, pleural } \\
\text { effusion, pneumothorax); assessed as an } \\
\text { aggregate score with normal breath sound; rules } \\
\text { out clinically significant airway obstruction* }\end{array}$ \\
\hline Bronchial breathing & $\begin{array}{l}\text { Soft, nonmusical, heard on both phases of respiratory } \\
\text { cycle (mimics tracheal sound) }\end{array}$ & $\begin{array}{l}\text { Indicates patent airway surrounded by consolidated } \\
\text { lung tissue (e.g., pneumonia) or fibrosis }\end{array}$ \\
\hline Stridor & $\begin{array}{l}\text { Musical, high-pitched, may be heard over the upper } \\
\text { airways or at a distance without a stethoscope }\end{array}$ & $\begin{array}{l}\text { Indicates upper-airway obstruction; associated with } \\
\text { extrathoracic lesions (e.g., laryngomalacia, vocal- } \\
\text { cord lesion, lesion after extubation) when heard } \\
\text { on inspiration; associated with intrathoracic } \\
\text { lesions (e.g., tracheomalacia, bronchomalacia, } \\
\text { extrinsic compression) when heard on expiration; } \\
\text { associated with fixed lesions (e.g., croup, paralysis } \\
\text { of both vocal cords, laryngeal mass or web) when } \\
\text { biphasic }\end{array}$ \\
\hline Wheeze & $\begin{array}{l}\text { Musical, high-pitched; heard on inspiration, } \\
\text { expiration, or both }\end{array}$ & $\begin{array}{l}\text { Suggests airway narrowing or blockage when localized } \\
\text { (e.g., foreign body, tumor); associated with } \\
\text { generalized airway narrowing and airflow } \\
\text { limitation when widespread (e.g., in asthma, } \\
\text { chronic obstructive lung disease); degree of } \\
\text { airflow limitation proportional to number of } \\
\text { airways generating wheezes; may be absent if } \\
\text { airflow is too low (e.g., in severe asthma, } \\
\text { destructive emphysema) }\end{array}$ \\
\hline Rhonchus & $\begin{array}{l}\text { Musical, low-pitched, similar to snoring; lower in } \\
\text { pitch than wheeze; may be heard on inspiration, } \\
\text { expiration, or both }\end{array}$ & $\begin{array}{l}\text { Associated with rupture of fluid films and abnormal } \\
\text { airway collapsibility; often clears with coughing, } \\
\text { suggesting a role for secretions in larger airways; } \\
\text { is nonspecific; is common with airway narrowing } \\
\text { caused by mucosal thickening or edema or by } \\
\text { bronchospasm (e.g., bronchitis and chronic } \\
\text { obstructive pulmonary disease) }\end{array}$ \\
\hline Fine crackle & $\begin{array}{l}\text { Nonmusical, short, explosive; heard on mid-to-late } \\
\text { inspiration and occasionally on expiration; } \\
\text { unaffected by cough, gravity-dependent, not } \\
\text { transmitted to mouth }\end{array}$ & $\begin{array}{l}\text { Unrelated to secretions; associated with various diseases } \\
\text { (e.g., interstitial lung fibrosis, congestive heart failure, } \\
\text { pneumonia); can be earliest sign of disease (e.g., } \\
\text { idiopathic pulmonary fibrosis, asbestosis); may be } \\
\text { present before detection of changes on radiology }\end{array}$ \\
\hline Coarse crackle & $\begin{array}{l}\text { Nonmusical, short, explosive sounds; heard on early } \\
\text { inspiration and throughout expiration; affected by } \\
\text { cough; transmitted to mouth }\end{array}$ & $\begin{array}{l}\text { Indicates intermittent airway opening, may be related } \\
\text { to secretions (e.g., in chronic bronchitis) }\end{array}$ \\
\hline Pleural friction rub & $\begin{array}{l}\text { Nonmusical, explosive, usually biphasic sounds; } \\
\text { typically heard over basal regions }\end{array}$ & $\begin{array}{l}\text { Associated with pleural inflammation or pleural } \\
\text { tumors }\end{array}$ \\
\hline Squawk & $\begin{array}{l}\text { Mixed sound with short musical component (short } \\
\text { wheeze) accompanied or preceded by crackles }\end{array}$ & $\begin{array}{l}\text { Associated with conditions affecting distal airways; } \\
\text { may suggest hypersensitivity pneumonia or other } \\
\text { types of interstitial lung disease in patients who } \\
\text { are not acutely ill; may indicate pneumonia in } \\
\text { patients who are acutely ill }\end{array}$ \\
\hline
\end{tabular}

* Information is from Bohadana et al. ${ }^{3}$ 
detail below). Finally, monitoring tracheal sounds is a noninvasive means of monitoring patients for the sleep apnea syndrome, although for practical reasons such monitoring cannot be performed by means of auscultation with a stethoscope. ${ }^{5}$ Whereas the stridorous breathing of a child with croup is easily recognized, stridor in adults, when caused by bronchial or tracheal stenosis or by a tumor in the central airway, is more subtle. It may be missed when only the lungs are examined but is obvious when heard over the trachea or larynx. ${ }^{6}$

\section{LUNG, OR "VESICULAR," SOUNDS}

The sound of normal breathing heard over the surface of the chest is markedly influenced by the anatomical structures between the site of sound generation and the site of auscultation. Characteristically, normal lung sounds are heard clearly during inspiration but only in the early phase of expiration (Fig. 1B). In sound analysis, the frequency range of normal lung sounds appears to be narrower than that of tracheal sounds, extending from below $100 \mathrm{~Hz}$ to $1000 \mathrm{~Hz}$, with a sharp drop at approximately 100 to $200 \mathrm{~Hz} .^{7}$ The idea that "vesicular" sound is produced by air entering the alveoli ("vesicles") is incorrect. Indeed, modern concepts of physiology indicate that in the lung periphery gas molecules migrate by means of diffusion from parts of the lung reached through bulk flow, a silent process. Most important, studies support the idea of a double origin, with the inspiratory component generated within the lobar and segmental airways and the expiratory component coming from more central sources. ${ }^{8,9}$

Several mechanisms of vesicular sounds have been suggested, including turbulent flow, vortexes, and other, hitherto unknown mechanisms. ${ }^{10-12}$ Clinically, a decrease in sound intensity is the most common abnormality. Mechanistically, this loss of intensity can be due to a decrease in the amount of sound energy at the site of generation, impaired transmission, or both. ${ }^{3}$ Sound generation can be decreased when there is a drop in inspiratory airflow, which can result from several conditions, ranging from poor cooperation (e.g., a patient's unwillingness to take a deep breath) to depression of the central nervous system (e.g., drug overdose). Airway conditions include blockage (e.g., by a foreign body or tumor) and the narrowing that occurs in obstructive
Figure 1 (facing page). Acoustics and Waveforms of Lung Sounds.

The left column shows typical values for the frequency (hertz) and duration (milliseconds) of the various sounds. The middle and right columns show amplitude-time plots in unexpanded and time-expanded modes, respectively (amplitude is measured in arbitrary units, and time in seconds). The unexpanded plots contain screenshots of the entire sound, with a vertical line showing where the time-expanded sections (200 msec) were obtained. All tracings begin with inspiration. The unexpanded waveform of the tracheal sound (Panel A) has strong inspiratory and expiratory components; the expanded waveform shows random fluctuations that are characteristic of white noise (a heterogeneous mixture of sound waves extending over a wide range of frequencies). The vertical, regular spikes correspond to heart sounds. The unexpanded waveform of a normal (vesicular) breath (Panel B) has a strong inspiratory component relative to the expiratory component; the expanded waveform is similar to that of a tracheal sound, with random variation in amplitude. (A low-pass filter allows easy passing of frequencies below a prescribed frequency limit.) In bronchial breathing (Panel C), the unexpanded waveform is characterized by similar amplitudes of the inspiratory and expiratory components; the time-expanded waveform is like that seen with tracheal and normal breath sounds. The unexpanded waveform of stridor (Panel D) has a strong inspiratory component that appears as sinusoidal oscillations in the time-expanded tracing. (The sinusoid is a waveform representing periodic oscillations of constant amplitude, as indicated by a sine function. The fundamental frequency is the lowest frequency produced.) The unexpanded waveform of a wheeze (Panel E) has a strong expiratory component, which appears as sinusoidal oscillations characteristic of musical sounds in the time-expanded tracing. A rhonchus (Panel F) can be distinguished from a wheeze by its lower frequency, evident in the lower number of oscillations per unit of time in the time-expanded waveform. In the unexpanded waveform, fine crackles (Panel G) appear as spikes that correspond with the rapidly dampened wave deflections seen in the time-expanded tracing. Coarse crackles (Panel $\mathrm{H}$ ) cannot be distinguished from fine crackles in the unexpanded waveform; however, their longer duration is apparent in the time-expanded tracing. The pleural friction rub (Panel I) has an unexpanded waveform characterized by a series of vertical spikes in a pattern that is undistinguishable from that produced by crackles. The lower frequency of the pleural friction rub is apparent in the time-expanded tracing. The short musical component of the squawk (Panel J) is seen in the unexpanded waveform as a large vertical spike in the middle of the inspiratory component of the normal breath sound. However, the sinusoidal oscillations typical of musical sounds are evident only in the time-expanded tracing. Numerous accompanying crackles can be seen as small vertical spikes on both inspiration and expiration. See the interactive graphic at NEJM.org. 


\begin{tabular}{|c|c|c|c|}
\hline & Respiratory Sound & \multicolumn{2}{|c|}{ Amplitude-Time Plot } \\
\hline & Acoustics & Unexpanded time & Expanded time \\
\hline A & $\begin{array}{l}\text { Tracheal Sound } \\
\text { White noise } \\
\text { Typical frequency, } 100-5000 \mathrm{~Hz} \\
\text { Drop of energy at } 800 \mathrm{~Hz}\end{array}$ & 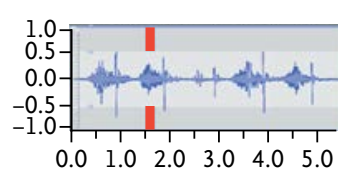 & 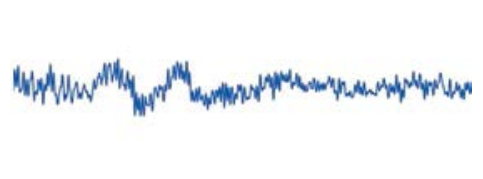 \\
\hline B & $\begin{array}{l}\text { Normal (Vesicular) Lung Sound } \\
\text { Low-pass-filtered noise } \\
\text { Typical frequency, } 100-1000 \mathrm{~Hz} \\
\text { Drop of energy at } 200 \mathrm{~Hz}\end{array}$ & 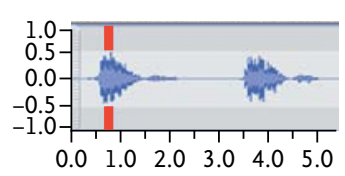 & 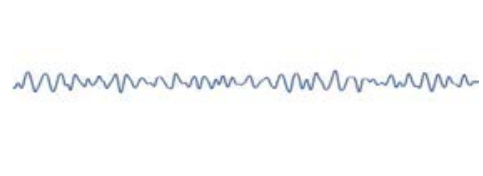 \\
\hline C & $\begin{array}{l}\text { Bronchial Breathing } \\
\text { Strong expiratory component } \\
\text { An intermediate sound between tracheal } \\
\text { and normal breathing }\end{array}$ & 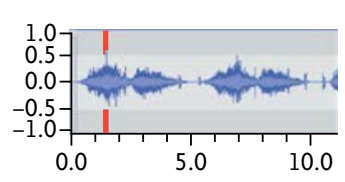 & 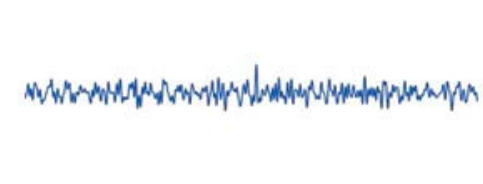 \\
\hline D & $\begin{array}{l}\text { Stridor } \\
\text { Sinusoid } \\
\text { Fundamental frequency, }>500 \mathrm{~Hz}\end{array}$ & 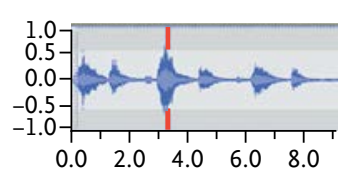 & 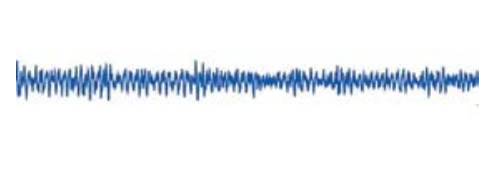 \\
\hline $\mathbf{E}$ & $\begin{array}{l}\text { Wheeze } \\
\text { Sinusoid } \\
\text { Typical frequency, }>100-5000 \mathrm{~Hz} \\
\text { Typical duration, }>80 \mathrm{msec}\end{array}$ & 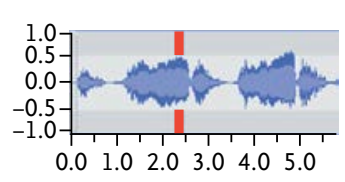 & 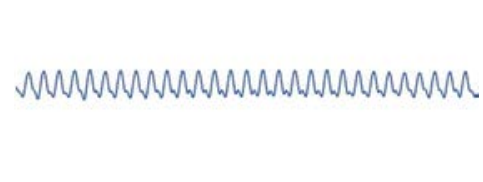 \\
\hline $\mathbf{F}$ & $\begin{array}{l}\text { Rhonchus } \\
\text { Sinusoid } \\
\text { Typical frequency, about } 150 \mathrm{~Hz} \\
\text { Typical duration, }>80 \mathrm{msec}\end{array}$ & 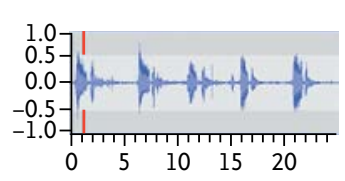 & WMMUMWMWMUMU \\
\hline G & $\begin{array}{l}\text { Fine Crackle } \\
\text { Rapidly dampened wave deflection } \\
\text { Typical frequency, about } 650 \mathrm{~Hz} \\
\text { Typical duration, about } 5 \mathrm{msec}\end{array}$ & 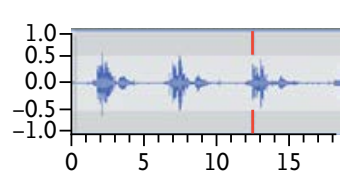 & 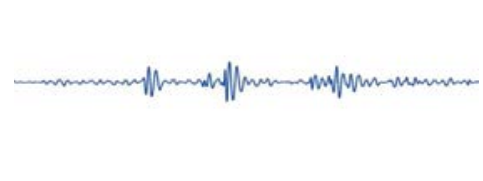 \\
\hline $\mathrm{H}$ & $\begin{array}{l}\text { Coarse Crackles } \\
\text { Rapidly dampened wave deflection } \\
\text { Typical frequency, about } 350 \mathrm{~Hz} \\
\text { Typical duration, about } 15 \mathrm{msec}\end{array}$ & 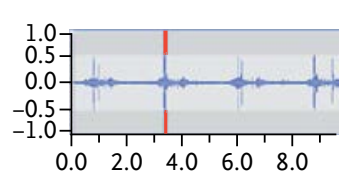 & \\
\hline I & $\begin{array}{l}\text { Pleural Friction Rub } \\
\text { Rhythmic succession of short sounds } \\
\text { Typical frequency, }<350 \mathrm{hz} \\
\text { Typical duration, }>15 \mathrm{msec}\end{array}$ & 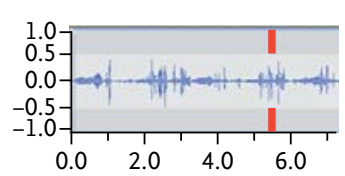 & 4 \\
\hline J & $\begin{array}{l}\text { Squawk } \\
\text { Sinusoid } \\
\text { Typical frequency, 200-300 Hz } \\
\text { Typical duration, about } 200 \mathrm{msec} \\
\text { Followed or preceded by crackles }\end{array}$ & 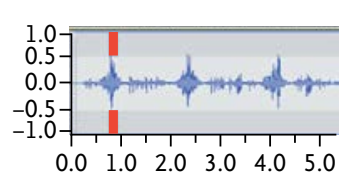 & 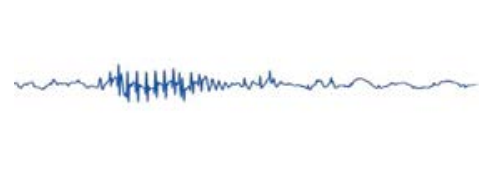 \\
\hline
\end{tabular}

The New England Journal of Medicine

Downloaded from nejm.org at UNIV OF KENTUCKY on October 20, 2015. For personal use only. No other uses without permission. 
airway diseases (e.g., asthma and chronic obstructive pulmonary disease [COPD]). The decrease in the intensity of breath sounds may be permanent, as in cases of pure emphysema, or reversible, as in asthma (e.g., during a bronchial provocation test ${ }^{13}$ or an asthma attack).

Sound transmission can be impaired by intrapulmonary or extrapulmonary factors. The latter include conditions such as obesity, chest deformities (e.g., kyphoscoliosis), and abdominal distention due to ascites. Intrapulmonary factors, which can be harder to recognize, include disruption of the mechanical properties of the lung parenchyma (e.g., a combination of hyperdistention and parenchymal destruction in emphysema) or the interposition of a medium between the source of sound generation and the stethoscope that has a different acoustic impedance from that of the normal parenchyma (e.g., collections of gas or liquid in the pleural space - pneumothorax, hemothorax, and intrapulmonary masses). Incidentally, the development of lung consolidation, which occurs in pneumonia, results in decreased breath sounds only if the embedded airways are blocked by inflammation or viscous secretions. If instead the airways are patent, sound transmission is actually improved, increasing the expiratory component; this effect is characterized as "bronchial breathing" (Fig. 1C), which corresponds to the air bronchogram on chest radiographs.

ABNORMAL RESPIRATORY SOUNDS

\section{MUSICAL SOUNDS}

Stridor

Stridor is a high-pitched, musical sound produced as turbulent flow passes through a narrowed segment of the upper respiratory tract. ${ }^{14}$ It is often intense, being clearly heard without the aid of a stethoscope. In sound analysis it is characterized by regular, sinusoidal oscillations with a fundamental frequency of approximately $500 \mathrm{~Hz}$, often accompanied by several harmonics (Fig. 1D). Evaluating stridor is especially useful in patients in the intensive care unit who have undergone extubation, when its appearance can be a sign of extrathoracic airway obstruction requiring prompt intervention. In cases of such obstruction, stridor can be distinguished from wheeze because it is more clearly heard on inspiration than on expiration and is more prominent over the neck than over the chest. ${ }^{14}$ Although stridor is usually inspiratory, it can also be expiratory or biphasic. Other causes of stridor in adults include acute epiglottitis, airway edema after device removal, anaphylaxis, vocal-cord dysfunction, inhalation of a foreign body, laryngeal tumors, thyroiditis, and tracheal carcinoma.

The stridorous sound of vocal-cord dysfunction deserves special mention because it is often confused with asthma and is responsible for numerous visits to the emergency department and hospitalizations. (Vocal-cord dysfunction, also called paradoxical vocal-cord motion, is a respiratory condition characterized by the inappropriate adduction of the vocal cord with resultant airflow limitation at the level of the larynx, accompanied by stridorous breathing.) In a review of 95 patients with vocal-cord dysfunction who were treated at the National Jewish Center, more than half carried an incorrect diagnosis of asthma for years and most had been treated with substantial doses of glucocorticoids. These patients also had an average of six hospitalizations yearly, and $28 \%$ had been intubated. ${ }^{15}$ In addition, several reports have documented the costs of misdiagnosed vocalcord dysfunction to the medical care system. ${ }^{16}$

\section{Wheeze}

The wheeze is probably the most easily recognized adventitious sound. ${ }^{17}$ Its long duration, typically more than $100 \mathrm{msec}$, allows its musical quality to be discerned by the human ear. In sound analysis the wheeze appears as sinusoidal oscillations with sound energy in the range of 100 to $1000 \mathrm{~Hz}$ and with harmonics that exceed $1000 \mathrm{~Hz}$ on occasion (Fig. 1E). ${ }^{18}$ It is probably incorrect to credit high-pitched wheezes to the narrowing of peripheral airways and low-pitched wheezes to the narrowing of central airways. Purportedly, wheezes are formed in the branches between the second and seventh generations of the airway tree by the coupled oscillation of gas and airway walls that have been narrowed to the point of apposition by a variety of mechanical forces. ${ }^{18}$ In addition, the model incorporates two principles: first, that although wheezes are always associated with airflow limitation, airflow can be limited in the absence of wheezes, and second, that the pitch of an individual wheeze is determined not by the diameter of the airway but by the thickness of the airway wall, bending stiffness, and longitudinal tension. ${ }^{18}$ 
Wheezes can be inspiratory, expiratory, or biphasic. Although typically present in obstructive airway diseases, especially asthma, they are not pathognomonic of any particular disease. In asthma and COPD, wheezes can be heard all over the chest, making their number difficult to estimate. Localized wheeze is often related to a local phenomenon, usually an obstruction by a foreign body, mucous plug, or tumor. Failure to recognize this type of wheeze can have serious consequences for patients, who often receive a misdiagnosis of "difficult-to-treat asthma"19 and are not referred to appropriate specialists for months or even years after the initial evaluation. Wheezes may be absent in patients with severe airway obstruction. In fact, the model cited above predicts that the more severe the obstruction, the lower the likelihood of wheeze. The typical example is a severe asthma attack, a condition in which the low respiratory flows cannot provide the energy necessary to generate wheezes (or any sounds). As a consequence, the accompanying normal breath sound is also severely reduced or even absent, creating a clinical picture known as "silent lung." As the obstruction is relieved and airflow increases, both the wheeze and normal breath sounds reappear.

Finally, a word must be said about the rhonchus. This sound is considered to be a variant of the wheeze, differing from the wheeze in its lower pitch - typically near $150 \mathrm{~Hz}$ - which is responsible for its resemblance to the sound of snoring on auscultation (Fig. 1F). ${ }^{17}$ The rhonchus and the wheeze probably share the same mechanism of generation, but the rhonchus, unlike the wheeze, may disappear after coughing, which suggests that secretions play a role. Although many physicians still use the term rhonchus, some prefer to refer to the characteristic musical sounds simply as high-pitched or low-pitched wheezes.

\section{NONMUSICAL SOUNDS}

\section{Crackles}

Crackles are short, explosive, nonmusical sounds heard on inspiration and sometimes during expiration. ${ }^{17}$ Two categories of crackles have been described: fine crackles and coarse crackles. On auscultation, fine crackles are usually heard during mid-to-late inspiration, are well perceived in dependent lung regions, and are not transmitted to the mouth. Uninfluenced by cough, fine crackles are altered by gravity, changing or disappearing with changes in body position (e.g., bending forward). Coarse crackles tend to appear early during inspiration and throughout expiration and have a "popping" quality. They may be heard over any lung region, are usually transmitted to the mouth, can change or disappear with coughing, and are not influenced by changes in body position. In sound analysis, crackles appear as rapidly dampened wave deflections with a repetitive pattern (Fig. 1G and 1H). As compared with coarse crackles, fine crackles have a shorter duration ( $5 \mathrm{msec}$ vs. $15 \mathrm{msec}$ ) and higher frequency $(650 \mathrm{~Hz}$ vs. $350 \mathrm{~Hz}){ }^{20}$ The most likely mechanism for the generation of fine crackles is the sudden inspiratory opening of small airways held closed by surface forces during the previous expiration. ${ }^{21}$ Coarse crackles are probably produced by boluses of gas passing through airways as they open and close intermittently. ${ }^{17}$ With the exception of the crackling sounds heard in moribund patients or in patients with abundant secretions, crackles are probably not produced by secretions.

Evaluation for crackles is important because it can help with the differential diagnosis. Because fine crackles have a distinctive sound that is similar to the sound heard when joined strips of Velcro are gently separated, they have been called Velcro rales. Typically, fine crackles are prominent in idiopathic pulmonary fibrosis, appearing first in the basal areas of the lungs and progressing to the upper zones with disease progression. ${ }^{22}$ However, fine crackles are not pathognomonic of idiopathic pulmonary fibrosis; they are also found in other interstitial diseases, such as asbestosis, nonspecific interstitial pneumonitis, and interstitial fibrosis associated with connective-tissue disorders. Notably, fine crackles tend to be minimal or even absent in sarcoidosis, probably because sarcoidosis primarily affects the central lung zones not abutting the pleura. Among patients with similar levels of scarring on chest films, those with few crackles are more likely to have sarcoidosis, whereas those who have many crackles are more likely to have idiopathic pulmonary fibrosis. Advanced computerized acoustic analysis, which involves the use of a multichannel sound-detection device, has made it possible to diagnose idiopathic pulmonary fibrosis and congestive heart failure, in addition to other cardiopulmonary disorders, with good sensitivity and specificity. ${ }^{23}$ 
In idiopathic pulmonary fibrosis and asbestosis, fine crackles can be discerned before radiologic abnormalities are detected and are thus considered to be an early sign of pulmonary impairment. ${ }^{24,25}$ Although the presence of Velcro rales as heard on auscultation has not been formally accepted as diagnostic of idiopathic pulmonary fibrosis, auscultation is considered to be the only realistic means of detection early in the course of the disease. ${ }^{22}$ In asbestosis, the use of computerized detection of crackles has appeared to be as accurate as CT in locating disease that is not radiologically apparent. ${ }^{25}$ In a study of 386 workers exposed to asbestos, ${ }^{26}$ crackle detection by means of auscultation performed by a trained technician correctly identified all the cases of asbestosis, suggesting that auscultation may have a role to play as a noninvasive method of screening in these populations.

Coarse crackles are commonly heard in patients with obstructive lung diseases, including COPD, bronchiectasis, and asthma, usually in association with wheezes. They are also often heard in patients with pneumonia and those with congestive heart failure. In pneumonia, the characteristics of the crackles may vary markedly during the disease: the coarse, midinspiratory crackles heard in the early phase give way to shorter, end-inspiratory crackles in the recovery phase. ${ }^{27}$ Fine and coarse crackles may also coexist. ${ }^{28}$ Finally, although crackles can be heard in healthy persons, the crackles tend to disappear after a few deep breaths. The presence of persistent crackles in both lungs in older persons with dyspnea should prompt an investigation for interstitial lung disease.

\section{Pleural Friction Rub}

In healthy persons, the parietal and visceral pleura slide over each other silently. In persons with various lung diseases, the visceral pleura can become rough enough that its passage over the parietal pleura produces crackling sounds heard as a friction rub. In our experience, this sound is more prominent on auscultation of the basal and axillary regions than on auscultation of the upper regions. One explanation for this difference is the fact that the basal regions lie on the steep portion of the static pressure-volume curve, whereas the upper regions lie on the flat portion of the curve. Thus, for a given change in trans- pulmonary pressure, the basal regions undergo greater expansion. Typically, the pleural friction rub is biphasic, with the expiratory sequence of sounds mirroring the inspiratory sequence. ${ }^{29}$ Figure 1I shows individual components of a pleural friction rub. The waveform is similar to that seen with crackles, except for its longer duration and lower frequency. The pleural friction rub is probably produced by the sudden release of tangential energy from a lung surface that is temporarily prevented from sliding because of a frictional force between the two pleural layers. ${ }^{29}$ Typically, pleural friction rubs are heard in inflammatory diseases (e.g., pleuritis) or malignant pleural diseases (e.g., mesothelioma).

\section{Mixed Sound - The Squawk}

Also called "short wheeze" or "squeak," the squawk is a mixed sound, containing musical and nonmusical components. Figure 1J shows the sound analysis for a recorded squawk in a patient with hypersensitivity pneumonitis. The short wheeze appears as sinusoidal oscillations that are less than $200 \mathrm{msec}$ in duration, with a fundamental frequency between 200 and $300 \mathrm{~Hz}$. The mechanism underlying the production of squawks is not entirely known, but according to one theory, they are produced by the oscillation of peripheral airways (in deflated lung zones) whose walls remain in apposition long enough to oscillate under the action of the inspiratory airflow. ${ }^{29}$ Squawks are typically heard from the middle to the end of inspiration in patients with interstitial diseases, especially hypersensitivity pneumonitis. ${ }^{30}$ However, they are not pathognomonic of this condition, having also been documented in diseases such as bronchiectasis and pneumonia. ${ }^{31}$ In a patient with squawk and no evidence of interstitial disease, pneumonia should be suspected, because it is the next most likely cause. ${ }^{31}$

\section{CONCLUSIONS}

Lung auscultation remains an essential part of the physical examination. No other clinical procedure matches auscultation for the provision of relevant clinical information about the respiratory system quickly, easily, and by nearly universally available means. Moreover, auscultation requires minimal cooperation on the part of the patient, is cost-effective, and can be repeated as 
often as necessary. The development of robust acoustic devices for use at the bedside - as exemplified by electronic stethoscopes paired with small convenient recorders, perhaps in the form of a smartphone with an app - may provide the long-awaited portable objective means to record, analyze, and store lung sounds just as any other clinical information is measured and stored. This development will make sound tracking possible, further enhancing the usefulness of auscultation. Finally, it must be kept in mind that auscultation is not a laboratory test but a component of the physical examination whose usefulness depends on its proper correlation with the available clinical information.

Dr. Izbicki reports receiving lecture fees from Novartis; AstraZeneca; Teva; Pfizer; Merck, Sharp, and Dohme; and Neopharm, travel support from Novartis and GlaxoSmithKline, and grant support from Novartis, GlaxoSmithKline, and AstraZeneca - all through his institution; and Dr. Kraman reports providing expert testimony in workers' compensation and medical malpractice cases. No other potential conflict of interest relevant to this article was reported.

Disclosure forms provided by the authors are available with the full text of this article at NEJM.org.

We thank Dr. Hans Pasterkamp for providing the stridor sound file, and Anto Yawanta and Jean-Pierre Michaely for their technical assistance in the recording and analysis of lung sounds.
REFERENCES

1. Laennec RTH. De l'auscultation médiate ou traité du diagnostic des maladies des poumons et du coeur. Paris: Brosson \& Chaudé, 1819.

2. Mikami R, Murao M, Cugell DW, et al. International Symposium on Lung Sounds: synopsis of proceedings. Chest 1987;92: 342-5.

3. Bohadana $A B$, Peslin $\mathrm{R}$, Uffholtz $\mathrm{H}$. Breath sounds in the clinical assessment of airflow obstruction. Thorax 1978;33: 345-51.

4. Gavriely N, Palti Y, Alroy G. Spectral characteristics of normal breath sounds. J Appl Physiol Respir Environ Exerc Physiol 1981;50:307-14.

5. Yadollahi A, Giannouli E, Moussavi Z. Sleep apnea monitoring and diagnosis based on pulse oximetry and tracheal sound signals. Med Biol Eng Comput 2010;48:1087-97.

6. Kraman SS, Harper P, Pasterkamp $\mathrm{H}$, Wodicka GR. 'Slide whistle' breath sounds: acoustical correlates of variable tracheal obstruction. Physiol Meas 2002;23:44955.

7. Gavriely $\mathrm{N}$, Nissan $\mathrm{M}$, Rubin AHE, Cugell DW. Spectral characteristics of chest wall breath sounds in normal subjects. Thorax 1995;50:1292-300.

8. Kraman SS. Determination of the site of production of respiratory sounds by subtraction phonopneumography. Am Rev Respir Dis 1980;122:303-9.

9. Kraman SS. Does laryngeal noise contribute to the vesicular lung sound? Am Rev Respir Dis 1981;124:292-4.

10. Austrheim O, Kraman SS. The effect of low density gas breathing on vesicular lung sounds. Respir Physiol 1985;60:145-55.
11. Bohadana AB, Kanga JF, Kraman SS. Does airway closure affect lung sound generation? Clin Physiol 1988;8:341-9. 12. Pasterkamp H, Sanchez I. Effect of gas density on respiratory sounds. Am J Respir Crit Care Med 1996;153:1087-92.

13. Bohadana AB, Peslin R, Uffholtz $H$, Pauli G. Potential for lung sound monitoring during bronchial provocation testing. Thorax 1995;50:955-61.

14. Baughman RP, Loudon RG. Stridor: differentiation from asthma or upper airway noise. Am Rev Respir Dis 1989;139: 1407-9.

15. Morris MJ, Christopher KL. Diagnostic criteria for the classification of vocal cord dysfunction. Chest 2010;138: 1213-23.

16. Butani L, O'Connell EJ. Functional respiratory disorders. Ann Allergy Asthma Immunol 1997;79:91-9.

17. Forgacs P. The functional basis of pulmonary sounds. Chest 1978;73:399-405.

18. Gavriely N, Shee TR, Cugell DW, Grotberg JB. Flutter in flow-limited collapsible tubes: a mechanism for generation of wheezes. J Appl Physiol (1985) 1989;66:2251-61.

19. Ravenna F, Caramori G, Panella GL, et al. An unusual case of congenital short trachea with very long bronchi mimicking bronchial asthma. Thorax 2002;57:372-3. 20. Munakata $M$, Ukita $H$, Doi I, et al. Spectral and waveform characteristics of fine and coarse crackles. Thorax 1991;46: 651-7.

21. Vyshedskiy A, Alhashem RM, Paciej $\mathrm{R}$, et al. Mechanism of inspiratory and expiratory crackles. Chest 2009;135:15664.
22. Cottin V, Cordier J-F. Velcro crackles: the key for early diagnosis of idiopathic pulmonary fibrosis? Eur Respir J 2012;40: 519-21.

23. Flietstra B, Markuzon N, Vyshedskiy A, Murphy R. Automated analysis of crackles in patients with interstitial pulmonary fibrosis. Pulm Med 2011;2011:590506.

24. Epler GR, McLoud TC, Gaensler EA, Mikus JP, Carrington CB. Normal chest roentgenograms in chronic diffuse infiltrative lung disease. N Engl J Med 1978; 298:934-9.

25. al Jarad N, Strickland B, Bothamley G, Lock S, Logan-Sinclair R, Rudd RM. Diagnosis of asbestosis by a time expanded wave form analysis, auscultation and high resolution computed tomography: a comparative study. Thorax 1993;48:347-53.

26. Murphy RL Jr, Gaensler EA, Holford SK, Del Bono EA, Epler G. Crackles in the early detection of asbestosis. Am Rev Respir Dis 1984;129:375-9.

27. Piirilä $\mathrm{P}$. Changes in crackle characteristics during the clinical course of pneumonia. Chest 1992;102:176-83.

28. Murphy R, Vyshedskiy A. Acoustic findings in a patient with radiation pneumonitis. N Engl J Med 2010;363(20):e31.

29. Forgacs P. Lung sounds. London: Baillière Tindall, 1978.

30. Earis JE, Marsh K, Pearson MG, Ogilvie CM. The inspiratory "squawk" in extrinsic allergic alveolitis and other pulmonary fibroses. Thorax 1982;37: 923-6.

31. Paciej R, Vyshedskiy A, Bana D, Murphy R. Squawks in pneumonia. Thorax 2004;59: 177-8.

Copyright (C) 2014 Massachusetts Medical Society.

RECEIVE THE JOURNAL'S TABLE OF CONTENTS EACH WEEK BY E-MAIL

To receive the table of contents of the Journal by e-mail every Wednesday evening, sign up at NEJM.org. 